\title{
Catz, Dogz \& Robotz? Human interaction with domestic robotic devices
}

\author{
Shaun Lawson and Thomas Chesney
}

\begin{abstract}
This special issue of the Journal of Physical Agents is devoted to human interaction with domestic robots. The form, features and future, of domestic robotic devices, from entertainment-based agents through to robotic cleaners, companions, assistants and helpers, are considered and discussed.
\end{abstract}

Index Terms - human-robot interaction (HRI), physical agents, domestic agents and applications.

\section{INTRODUCTION}

I $\mathrm{N}$ the future, humans will be expected to engage in interactions with embodied robotic systems that are truly ubiquitous [1], [2]. Many such interactions are likely to be situated in public places a person is greeted by a service robot when they enter a museum or shopping centre, a traveler checks into a hotel and the luggage is taken by a robotic busboy, a survivor of a collapsed building encounters a rescue robot as it penetrates the debris around them. Many other interactions however will take place in domestic environments. Indeed the major commercial successes to date in consumer robotics have all been devices, such as the iRobot Roomba and WoWees RoboSapien, intentionally built for the domestic home.

This special issue of the Journal of Physical Agents is devoted to human interaction with domestic robots. It was conceived following the successful staging of two international symposia entitled "The Reign of Catz and Dogz: the role of virtual creatures in a computerised society", the first of which was held at the Society for the Study of Artificial Intelligence and Simulation of Behaviour (AISB) annual conference in Newcastle (UK) in April 2007, and the second at AISB 2008 in Aberdeen (UK) in April 2008. The "Catz \& Dogz" symposia aimed to explore aspects of interaction with anthropomorphised and domestic technology such as Aibo, Pleo, Paro and Nabaztag, as well as software such as Catz, Dogz, (fluff)Friends, Neopets and Nintendogs, as well as the numerous non-commercial devices and systems that have been developed in many research labs. The world-wide popularity of many examples of such artifacts provides evidence of the widespread appeal of interacting with artificial representations of creatures, however the academic investigation of such interactions remains scarce. The two symposia to date, both chaired by the guest editors of this issue, have attracted not

Shaun Lawson is with University of Lincoln.

E-mail: slawson@lincoln.ac.uk

Thomas Chesney is with Nottingham University Business School. E-mail: thomas.chesney@nottingham.ac.uk only contributions centred upon software agents but also many on interaction with embodied interactive and social robots.

The notion of social robots - and human interaction with them - has, in recent years, spawned a new, and interdisciplinary, academic field: that of Human Robot Interaction (HRI). HRI however is still very much in its infancy in a worldwide context. Japan, with its aging population and low birth rate, has long fostered research in areas which could, in the long term, provide autonomous, but socially acceptable, assistive-care for older people. Additionally, it is often speculated (for example [3]) that cultural differences in the Far East result in a much more comfortable acceptance of the notion of living machines when compared to the skepticism and irony that often greets notions of commercial social robots in, for instance, Europe and the US (for example [4]). Tellingly, therefore, the first eight annual IEEE International Workshops on Robot and Human Interactive Communication (RO-MAN) were held in Japan (starting in 1992). However, since 2000, RO-MAN workshops have also been held in Europe and the US, whilst the First Annual ACM Conference on HumanRobot Interaction (HRI) was held in Salt Lake City, USA, in 2006 followed by events in Washington (USA) in 2007 and in Amsterdam (the Netherlands) in 2008 (both co-sponsored by ACM/IEEE). Furthermore, both of the IEEE Robotics and Automation Society (RAS) flagship meetings in 2008, the International Conference on Robotics and Automation (ICRA) and the International Conference on Intelligent RObots and Systems (IROS) both incorporated themes of humans coexisting with robots in their main calls thus demonstrating the burgeoning nature, and contemporary importance of HRI.

It was in this context therefore that we solicited papers for a special issue of JoPhA early in 2008 devoted to human interaction with domestic robots. We received a very enthusiastic response to the call and reluctantly had to reject many papers that were of a high quality but fell outside of the theme of the issue. Several outstanding and highly innovative pieces of work from Catz and Dogz 08 such as the Haptic Creature project at UBC [5] - also werent available due to time constraints on publication. In the event we have accepted six papers all broadly situated within the theme of interaction with robots in a domestic setting.

The accepted papers reflect the complexities and, especially, the inter-disciplinary issues, currently facing HRI researchers: some papers included in this issue are focused on systems and engineering design whilst others report on experiments involving user groups; several of the papers in the latter category also incorporate methodologies originally forged in the human computer interaction domain such as Wizard-of- 
$\mathrm{Oz}$ (WoZ) techniques [6]. The melding of research work in systems design together with user experimentation work is a difficult challenge for HRI researchers - and one that was discussed, along with issues such as WoZ approaches, at length at the NEWHRI workshop at IEEE ICRA 08 [7] attended by many of the discipline's leading researchers.

\section{THIS ISSUE CONTENT}

The first paper in this special issue by Saldien et al. [8] falls into the category of a systems design contribution - the authors describe their approach to the construction of a novel interactive robot called Probo - a device intended to act as a therapeutic companion for children when in hospital. Probo draws immediate comparison with devices such as the MIT Huggable [9] but also features a highly novel morphology and a constrained target user group which shows great future potential. The second paper in this issue by Looije et al. [10] also addresses the future role of robots as companions and supporting characters for children; however this paper not only has its focus more in the domain of a user study (it uses the well-known Philips iCat [11] as an off-the-shelf interactive robot) but also addresses the difficult issue of embodiment in HRI - comparing a physical device with both a virtual representation of the same thing as well as a text interface.

The issues surrounding robot appearance and behaviour is a highly debated topic with many other authors elsewhere experimentally comparing different scenarios (for example [12], [13], [14], [15]. Individual differences in human subjects psychological impressions of social agents is also a difficult and intensely debated issue [16]. A great deal of HRI research currently involves humanoid robots - however, it is often predicted that mismatches between the appearance and ability of such robots could render interactions with them problematic (for example [17]). Much has also been written about the role of the uncanny valley in HRI and the problems with robots that fall through the cracks of human-like behaviour [18]. The third paper in this special issue by Lohse et al. [19] makes a contribution to this debate by comparing human reactions to a number of different robots - including a humanoid device.

The next paper by Heerink [20] also makes use of the iCat in a user study - this time in an application featuring older people as end-users. The idea that the older population might find great benefit in the future from social robots has great potential though its an area that also raises complex ethical issues [21]. The fifth and penultimate paper in this issue, by Lee et al. [22] returns to the style of a systems design contribution and describes the development of the robot, and its sensor systems, which went on to win the newly formed RoboCup@Home 2007 competition. The final paper in this issue by Jacobsson et al. [23] describes a new kind of robot for HRI all the way through concept, design and finally to evaluation - this paper emphasizes to us that the robots that will exist in everyday environments of the future will take on many different forms and purposes. We are reminded, in this respect, of innovative new commercial devices for the home such as the Nabaztag and the Sony Rolly - and we predict many more novel robotic systems like these will before long move from research lab to the domestic home.

\section{ACKNOWLEDGMENT}

We would like to thank the reviewers of the papers submitted for this special issue as well as the chairs respectively of AISB 2007 and 2008 for their support of Catz and Dogz.

\section{REFERENCES}

[1] K. Dautenhahn, B. Ogden and T. Quick, "From embodied to socially embedded agents-implications for interaction-aware robots. Cognitive Systems Research 3(3):397-428, 2002.

[2] B. Gates, "A robot in every home". Sceintific American January 2007.

[3] M. Kusahara, "The art of creating subjective reality: an analysis of Jananese digital pets. In C. Maley and E. Boudreau (eds), Artificial Life VII Workshop Proceedings, 2000.

[4] G. Musser, "Robots that suck: have they finally come out witha robot for the rest of us? Scientific American, Febuary 2003.

[5] S. Yohanan and K. E. MacLean, "The haptic creature project: social human-robot interaction through affective touch. In Proceedings of the AISB 2008 Symposium on The Reign of Catz and Dogz: The Second Symposium on the Role of Virtual Creatures in a Computerised Society, 1:7-11, Aberdeen, UK, 2008.

[6] D. Maulsby, S. Greenberg and R. Mander, "Prototyping an intelligent agent through Wizard of Oz'. In Proceedings of CHI'93, The Netherlands, ACM Press, 1993.

[7] NEWHRI: Unifying characteristics of research in human-robot interaction. Workshop at IEEE ICRA 2008, Pasadena, California. See: http://newhri.cs.brown.edu/Home.html

[8] J. Saldien, K. Goris, S. Yilmazyildiz, W.Verhelst and D. Lefeber "On the design of the huggable robot Probo", Journal of Physical Agents 2(2), June, 2008.

[9] W. D. Stiehl, J. Lieberman, C. Breazeal, L. Basel, R. Cooper, H. Knight, L. Lalla, A. Maymin and S. Purchase, "The huggable: a therapeutic robotic companion for relational, affective touch", IEEE Consumer Communications and Networking Conference, Las Vegas, US, 2006.

[10] R. Looije, M. A. Neerincx and V. de Lange. "Children's responses and opinion on three bots that motivate, educate and play", Journal of Physical Agents 2(2), June, 2008.

[11] A. J.N. Van Breemen, K. Crucq, B. J.A. Krose, M. Nuttin, J. M. Porta and E. Demeester, "A user-interface robot for ambient intelligent environments", in Proceedings of ASER 2003, Bardolino, Italy, 2003.

[12] C. F. DiSalvo, F. Gemperle, J. Forlizzi and S. Kiesler, "All robots are not created equal: the design and perception of humanoid robot heads", In Proceedings of DIS 2002 New York, ACM, 2002.

[13] S. L. Lee and S. Kiesler, "Human mental models of humanoid robots" In Proceedings of IEEE ICRA 2005, Spain, 2005.

[14] C. Bartneck, J. Reichenbach and J. Carpenter, "Use of praise and punishment in human-robot collaborative teams", In Proceedings of the RO-MAN 2006, Hatfield, UK, 2006.

[15] T. Komatsu and S. Yamada, "How do robots agents' appearances affect people's interpretations of the agents' attitudes?" In Proceedings of ACM CHI 2007.

[16] K. F. MacDorman and P. H. Khan Jr., "Psychological benchmarks of human-robot interaction", Interaction Studies 8(3): 359-362, 2007.

[17] B. Duffy, "Anthropomorphism and the social robot", Robotics \& Autonomous Systems 42: 177-190, 2003.

[18] K. F. MacDorman and H. Ishiguro, "Opening Pandora's uncanny box", Interaction Studies, 7: 361-368, 2006.

[19] M. Lohse, F. Hegel, and B. Wrede, "Domestic Applications for Social Robots-an online survey on the influence of appearance and capabilities", Journal of Physical Agents 2(2), June, 2008.

[20] M. Heerink, B. Kröse, V. Evers and B. Wielinga, "The influence of social presence on acceptance of a companion robot by older people", Journal of Physical Agents 2(2), June, 2008.

[21] R. Sparrow and L. Sparrow, "The the hands of machines? The future of aged care", Minds and Machines 16: 141-161, 2006.

[22] J. Lee, W. Bradley Knox and P. Stone, "Inter-classifier feedback for human-robot interaction in a domestic setting", Journal of Physical Agents 2(2), June, 2008.

[23] M. Jacobsson, Y. Fernaeus and L. E. Holmquist, "GlowBots: Designing and Implementing Engaging Human-Robot Interaction", Journal of Physical Agents 2(2), June, 2008. 